\title{
Qatar's Natural Sustainability: Plans, Perceptions, and Pitfalls
}

Mari Luomi
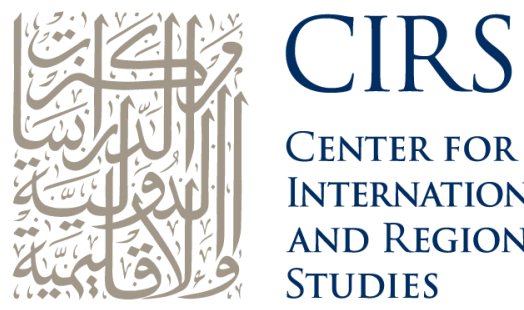

CENTER FOR INTERNATIONAL AND REGIONAL STUDIES

GEORGETOWN UNIVERSITY SCHOOL OF FOREIGN SERVICE IN QATAR

(C) 2012 


\section{Qatar's Natural Sustainability: \\ Plans, Perceptions, and Pitfalls}

Mari Luomi

(C) 2012 Center for International and Regional Studies Georgetown University School of Foreign Service in Qatar

Occasional Paper No. 11

ISSN 2072-5957 


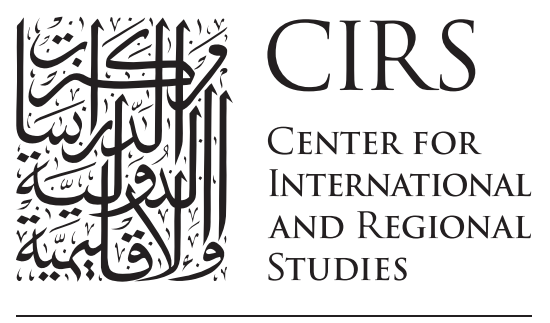

GEORGETOWN UNIVERSITY

SCHOOL OF FOREIGN SERVICE IN QATAR

Established in 2005, the Center for International and Regional Studies at the Georgetown University School of Foreign Service in Qatar is a premier research institute devoted to the academic study of regional and international issues through dialogue and exchange of ideas, research and scholarship, and engagement with national and international scholars, opinion makers, practitioners, and activists.

Guided by the principles of academic excellence, forward vision, and community engagement, the Center's mission revolves around five principal goals:

- To provide a forum for scholarship and research on international and regional affairs

- To encourage in-depth examination and exchange of ideas

- To foster thoughtful dialogue among students, scholars, and practitioners of international affairs

- To facilitate the free flow of ideas and knowledge through publishing the products of its research, sponsoring conferences and seminars, and holding workshops

designed to explore the complexities of the twenty-first century

- To engage in outreach activities with a wide range of local, regional, and international partners.

This publication series is made possible by the generous support of Qatar Foundation for Education, Science and Community Development. 


\section{Qatar's Natural Sustainability: \\ Plans, Perceptions, and Pitfalls}

Mari Luomi

Mari Luomi is Research Associate at the Georgetown University School of Foreign Service in Qatar. She was a Post-Doctoral Fellow at the Center for International and Regional Studies (CIRS), Georgetown University School of Foreign Service in Qatar, for the academic year 2011-2012. Luomi holds a Ph.D. in Middle Eastern Studies from Durham University. She has previously worked in various positions at the Finnish Institute of International Affairs. Luomi's research focuses on the domestic and international politics of climate change and political economy of natural resources and environmental sustainability in the Gulf. She is author of The Gulf Monarchies and Climate Change: Abu Dhabi and Qatar in an Era of Natural Unsustainability (London: Hurst, 2012). 



\section{Preface}

We cannot "grow" into sustainability. ${ }^{1}$

Growth in Qatar in the past decade has been tremendous: the total population has increased by one million and the economy has grown four-fold, leading to the skyrocketing of energy and water demand and greenhouse gas emissions. ${ }^{2}$ This research paper argues that a crucial question in need of answering is: how important is the environment for Qatar? Fast growth in population and natural resource consumption, together with a pronounced emphasis on economic growth, have had devastating impacts on the country's environmental and sustainability performance. Recently ranked as the country with the world's highest ecological footprint, ${ }^{3}$ Qatar urgently needs to balance its natural resource use with the local environmental and ecosystem limits so as to ensure prosperity for its people and the environment far into the future. The same question applies to Qatar's neighboring monarchies, which share very similar economic and demographic dynamics as well as similar political and climatic conditions.

In 2008 and 2011, Qatar's development planning agency, the General Secretariat for Development Planning (GSDP), launched two key documents, which set the goals for the country's development up to 2030 and for the current five-year period (201116), respectively. These plans recognize the environmental unsustainability of the fastpaced development in recent years, and prescribe some measures to improve the current state of affairs. However, as this paper argues, due to their specific understanding of what constitutes sustainable development, the documents do not sufficiently address the many problems and challenges. By proposing an alternative standpoint and by including the views of over a dozen Qatar-based experts, this study seeks to address constructively existing problems and potential pitfalls, and suggests more functional solutions.

I am grateful for the support of the Center for International and Regional Studies at the Georgetown University School of Foreign Service in Qatar for funding my research for the academic year 2011-12. I am also thankful to the Qatar-based "green stakeholders" who took time to share their valuable insights into this pressing issue. Furthermore, I would like to encourage readers of this paper to take note of Renee Richer's paper "Conservation in Qatar: Impacts of Increasing Industrialization," published in the CIRS Occasional Paper series in 2008, which has been an important contribution to the still very scarce literature on regional and local environmental challenges.

\footnotetext{
${ }^{1}$ Robert Goodland, “The Concept of Environmental Sustainability," Annual Review of Ecology and Systematics 26 (1995): 5.

${ }^{2}$ Qatar Statistics Authority, http://qsa.gov.qa/; World Resources Institute, “Climate Analysis Indicators Tool," June 2011. Estimates for emissions are only available until 2007, while Qatar's liquefied natural gas production more than doubled in 2007-2011.

${ }^{3}$ Global Footprint Network, National Footprint Accounts 2010 Edition, http://www.footprintnetwork.org.
} 



\begin{abstract}
This paper analyzes Qatar's present and future challenges relating to natural resources and environmental sustainability through the concept of "natural sustainability," which is defined as the use of natural resources in a way that ensures prosperity for humans and the environment, presently and in the future. By doing so, it proposes an alternative standpoint on sustainable development. The paper asks three broad questions: How is the relationship between development, economy, and the environment understood by different actors in Qatar? What implications do these different views have for planning and definition of desired outcomes in the areas of natural resource use and environmental sustainability? What can a more environment-centered focus contribute toward solving the existing unsustainabilities of development in Qatar and the Gulf Cooperation Council (GCC)? By refocusing attention from the economy and growth to the environment and its limits; and from technology and efficiency to institutions, people, and resourcefulness, Qatar and the GCC states might be able to avoid an impending collapse stemming from their fast exacerbating natural unsustainability.
\end{abstract}

Through the concept of "natural sustainability," defined as the use of natural resources in a way that ensures prosperity for humans and the environment presently and in the future, this paper analyzes Qatar's challenges relating to natural resources and environmental sustainability. It proposes an alternative standpoint on sustainable development, which shifts the objective of sustainability from the economy, growth, and consumerism, towards the environment, equilibrium, and resourcefulness. The paper asks three broad questions: How is the relationship between development, economy, and the environment understood by different actors in Qatar? What implications do these different views have for planning and definition of desired outcomes in the areas of natural resource use and environmental sustainability? What can a more environmentcentered focus contribute toward solving the existing unsustainabilities of development in Qatar and the Gulf Cooperation Council (GCC)?

The paper is based on the proposition that the political economies and systems of the contemporary Gulf monarchies, including Qatar, have produced a cycle of natural unsustainability that is hard to break away from. This condition can be examined 
quantitatively through the use of comparative indicators. The "ecological footprint," developed in the 1990s, is one of the most widely used existing aggregate indicators for measuring the impacts and limits of human demand on the Earth's resources. ${ }^{1}$ According to the latest Global Footprint Network data, Qatar has the world's largest ecological footprint: each year, each inhabitant consumes and pollutes, on average, 6.5 times the Earth's carrying capacity (per person, in 2008). ${ }^{2}$ Alternatively, the condition of natural unsustainability can be analyzed qualitatively, which is the the prime method in this paper, by examining available data, studies, and public documents, and by conducting expert survey interviews.

This paper analyzes this built-in unsustainability in the case of Qatar. It explores how and why challenges and responses in the areas of natural resource use and environmental sustainability are perceived and presented in the way they are by two different sources: official Qatari government development planning documents and Qatar-based "green stakeholders." In the study, green stakeholders are defined as people who have - or seek to have - a stake in increasing Qatar's natural sustainability based on their professional positions and/or expertise. Data for the study was collected in April-May 2012 from a varied selection of experts identified by the author. To focus the debate, selection was guided by the need for the expert to be aware of the basic debates on sustainable development in Qatar and elsewhere, to have spent years in Qatar (if expatriate), and to be working in a position related to Qatar's environmental challenges or responses to those challenges. ${ }^{3}$ Of the twenty-seven contacted experts, thirteen took the semi-structured questionnaire. ${ }^{4}$ Despite the small sample size, the respondents, who were granted anonymity, represented different nationalities, including Qatari, and all main sectors from government, to local and international businesses and industries, to civil society and research institutions. The sample's value, therefore, comes from the qualitative concentration of selected expert views, rather than its quantitative statistical representativeness.

The first section of this paper positions the study theoretically and conceptually by presenting some of the most important global debates on the relationship between development, economy, and the environment. This is followed by an empirical analysis, consisting of sections two through four. The second section examines how the government (through its planning documents) and stakeholders (through questionnaire responses) perceive the natural sustainability issue on a meta-level through two

\footnotetext{
${ }^{1}$ Mathis Wackernagel and William Rees, Our Ecological Footprint: Reducing Human Impact on the Earth (Gabriola Island: New Society Press, 1996).

${ }^{2}$ Global Footprint Network, National Footprint Accounts 2010 Edition, http://www.footprintnetwork.org; for a further discussion on the indicator's methodology and basic assumptions, see Appendix 1.

${ }^{3}$ The limitations to the selection of experts, which relate to general unwillingness of those involved in the public and oil/gas sector to speak openly about issues perceived as potentially problematic or sensitive is shared by social science students of Qatar and, to some extent, other GCC states.

${ }^{4}$ See the questionnaire in Appendix 2.
} 
questions: How is sustainable development understood? What worldviews underpin understandings of growth and system limits?

The third and fourth sections provide a practically-oriented account of the problems and challenges of natural resource use and its impacts on environmental sustainability in Qatar. The third section examines how these are defined in the planning documents and how they are perceived by the stakeholders. The fourth section analyzes the corresponding policy and management solutions and responses offered by both sources.

The fifth section ascends again to a more conceptual level by examining the question of responsibility. It also outlines Qatar's key natural sustainability obstacles by drawing from the preceding analysis and from specific questionnaire replies. This section also assesses the appropriateness of the government's selection of policy and management tools and proposes some alternatives. The paper concludes by answering the three main questions of the study. By re-examining Qatar's major natural sustainability challenges-including potential pitfalls in the current plans-from an alternative angle, the paper seeks to provide constructive support for environmentally sustainable development planning region-wide.

\section{Natural Sustainability Conceptualized}

\section{Sustainable Development Debates}

Because of its emphasis on natural resources and their relationship with environmental sustainability in a national-level context, this paper takes part in the debates on sustainable development (SD) from a specific angle. Many debates on SD deal with the "system level" (the Earth) and involve discussions on transboundary issues and complex debates over international poverty and inequity, which necessarily are largely excluded from this paper due to its country-level focus. While emphasizing the regionand country-specific context of the Gulf and Qatar, this section positions the paper theoretically and conceptually in the broader literature on SD.

There are dozens of recorded definitions of sustainable development, the most famous being from the Brundtland Report, which ambiguously defines it as "development that meets the needs of the present without compromising the ability of future generations to meet their own needs." ${ }^{5}$ The variety of existing definitions of $\mathrm{SD}$ and their diverging interpretations reflect the fundamental differences that exist in worldviews, values, and priorities among nations, professions, and individuals on: the value and role of nature; attitudes to economic growth and system limits; and the order of priority and substitutability of natural capital, among other issues.

\footnotetext{
${ }^{5}$ World Commission on Environment and Development, Our Common Future (Oxford: Oxford University Press, 1987), 43.
} 
The three-pillar approach to sustainable development (economic, social, and environmental sustainability) is widely used and quoted in the literature, but the relative weight given to its economic and environmental pillars varies greatly. Some recognize only the instrumental value of nature, and place humans at the center of SD, while others emphasize nature's intrinsic worth, with environmental sustainability as the core aim. There is, however, broad agreement on the idea of "intergenerational justice:" that $\mathrm{SD}$ is fundamentally about balancing the use of the Earth's natural resources so as to conserve them for the future. Intergenerational justice also resonates particularly deeply in the "neotraditional" legitimization discourses of contemporary Gulf societies. ${ }^{6}$

A major source of disagreement lies in what is to be sustained: the economy or ecosystems. ${ }^{7}$ The debate on $\mathrm{SD}$ is essentially one between growth and limits. It started four decades ago with the publication of a book titled Limits to Growth, commissioned as a report for the Club of Rome, which introduced the idea of carrying capacity, arguing that there are constraints to resource use and emissions that would have to be heeded. ${ }^{8}$ Growth in population and resource use would render these physical limits visible in the twenty-first century in the form of resource scarcity and environmental and food crises. Technology, the third driver in (un)sustainability, can only partially extend the limits. ${ }^{9}$

Malthusian in spirit, the idea that economic growth cannot continue indefinitely has met with strong criticism particularly among mainstream economists. These technology optimists argue that there are "no limits to growth in ingenuity;" quality of life will only continue to improve because technological development will decouple economic growth from growth in material consumption. ${ }^{10}$

Ecological modernization (EM) is often perceived as striking a balance between these two extremes. Its post-2008 variants are green development/economy/ growth, which in addition seek to take advantage of the current global economic crisis to refocus policies and investments. Rhetorically appealing, the theory of EM focuses on "the 'win-win' advantages of institutional and technological changes" and

\footnotetext{
${ }^{6}$ Consider, for example, the case of Sheikh Zayed bin Sultan Al Nahyan of Abu Dhabi, known across the region for his "environmental legacy;" Gerd Nonneman has described the use of traditional symbols for power legitimization in post-traditional GCC societies in "Political Reform in the Gulf Monarchies: From Liberalisation to Democratisation? A Comparative Perspective,”Working Paper, Centre for Middle Eastern and Islamic Studies, University of Durham, 2006, section 2.

${ }^{7}$ Ingolfur Blühdorn and Ian Welsh, eds., "Eco-Politics beyond the Paradigm of Sustainability: A Conceptual Framework and Research Agenda," in The Politics of Unsustainability: Eco Politics in the Post-Ecologist Era (Oxon: Routledge, 2008), 5.

${ }^{8}$ Donella H. Meadows, Jorgen Randers, and Dennis Meadows, Limits to Growth: The 30-Year Update (White River Junction: Chelsea Green, 2004), $x$-xi.

${ }^{9}$ Dennis Pirages and Ken Cousins, eds., From Resource Scarcity to Ecological Security (Cambridge: MIT, 2005), ix-x.

${ }^{10}$ Ibid., ix; Ken Cousins, "Twenty-Nine Days: Responding to a Finite World," in From Resource Scarcity to Ecological Security, eds., Dennis Pirages and Ken Cousins (Cambridge: MIT, 2005), 225.
} 
"decoupling through eco-efficiency." Some realize the difficulties of doing this, given the entrenchment of interests: prominent advocate of solar energy Herman Scheer, for example, saw that nothing short of a revolutionary structural change would be required for a global transition to renewable energy. ${ }^{12}$ However, as critics have noted, EM fails to challenge the growth paradigm, and its focus on efficiency overshadows the pressing need for simultaneous social and cultural change. ${ }^{13}$ Presumably for this reason, although primarily a Western discourse, elements of EM are being readily adopted in the Gulf monarchies, which seek to maintain not only the status quo of economic growth, but that of power (by maintaining the intricate social contracts that underpin it) as well. Another problem with efficiency is described by the Jevons paradox, which argues that technological gains in the efficiency of resource use tend to lead to an increase in consumption. ${ }^{14}$ Unfortunately, few tangible limits-centered paradigms have been put forward-with perhaps the exception of the radical, Western-centric theories on a/degrowth.

The disagreement over hierarchy and substitutability is a central feature of the SD debate. Arguably, another fundamental flaw in the prevalent SD/EM discourse espoused by governments, industries, and businesses is that it is based on a weak notion of SD, also known commonly as the triple bottom line. Weak SD gives equal weight to the three pillars of sustainability. It also tends to assume that different types of capital are substitutable: for example, that growth in industrial capital can offset losses in natural resources and ecosystem services as long as welfare levels are maintained. In other words, to achieve intergenerational sustainability, the advice given by the weak SD discourse is simply to keep a nation's total capital constant: "invest all profits or rents from exhaustible resources in reproducible capital." 15

Strong SD, in turn, sets the three pillars in a concentric hierarchy where environmental sustainability forms the basis of all other forms of sustainability. Most natural resources are not substitutable by human-made capital. Rather, these are complementary, and nothing can replace permanent loss of, for example, biodiversity or depleted groundwater reserves. A looser interpretation of strong SD allows for

\footnotetext{
${ }^{11}$ Susan Baker, "Sustainable Development as Symbolic Commitment: Declaratory Politics and the Seductive Appeal of Ecological Modernisation in the European Union," in The Politics of Unsustainability: Eco Politics in the Post-Ecologist Era, ed., Ingolfur Blühdorn and Ian Welsh (Oxon: Routledge, 2008), 115-20.

${ }^{12}$ Herman Scheer, Energy Autonomy: The Economic, Social and Technological Case for Renewable Energy (London: Earthscan, 2007).

${ }^{13}$ Baker, "Symbolic Commitment," 115-20. Baker has identified four main themes in related literature: focus on synergies between economic growth and environmental protection through top-down economic reorientation and promotion of R\&D; cross-sector environmental policy integration; economic instruments (including fiscal reform); and technological solutions, particularly in the industrial sector.

${ }^{14}$ Mathis Wackernagel and William E. Rees, "Perceptual and Structural Barriers to Investing in Natural Capital: Economics from and Ecological Footprint Perspective," Ecological Economics 20 (January 1997): 18-20.

${ }^{15}$ John M. Hartwick, "Intergenerational Equity and the Investing of Rents from Exhaustible Resources," The American Economic Review 67 (December 1977): 972.
} 
some flexibility: for instance, oil reserves can be depleted if they are invested in other types of capital. ${ }^{16}$ Furthermore, strong SD tends to stress that material consumption and consumerism should not become ends in themselves; instead of focusing on the resource equation as weak $\mathrm{SD}$ does, strong $\mathrm{SD}$ emphasizes adjusting demand patterns. ${ }^{17}$ This paper takes a normative stance on a number of issues, as outlined above, including: belief in nature's intrinsic value; the need for stronger sustainability and attention to the demand side of the equation; and the general unsubstitutability of natural capital. ${ }^{18}$

\section{Concept of Natural Sustainability}

A naturally sustainable state is defined here as one where the consumption of natural resources, renewable and non-renewable, is in a balanced relationship with the surrounding environment (i.e. environmental sustainability) and ensures the prosperity of both in the present and future (i.e. broad intergenerational justice). Natural sustainability takes a narrower and more defined focus on the topic than the Brundtland definition of SD. The concept of natural sustainability is introduced to clearly indicate the issue under focus: natural resource use, and the area in which it is evaluated, i.e. its impacts on the environment ("nature") and environmental sustainability. Environmental sustainability is a more precise and self-explanatory concept, defined by Baker as "preservation of natural environmental systems and processes, or addressing environmental issues to maintain social institutions and processes." ${ }^{19}$ Also, the concepts of environmental or ecological security and natural security are closely related to natural sustainability: a naturally sustainable political economy is also more likely to achieve security in these key areas. ${ }^{20}$ Importantly, relating to the economy, natural sustainability

\footnotetext{
${ }^{16}$ Wouter Van Dieren, ed., Taking Nature Into Account: A Report to the Club of Rome: Toward a Sustainable National Income (New York: Springer, 1995), 103-4.

${ }^{17}$ They also add the notion of moderate SD, which "seeks to both expand the stock of resource and reduce demands in this stock," Colin C. Williams and Andrew C. Millington, "The Diverse and Contested Meanings of Sustainable Development," The Geographical Journal 170 (June 2004): 100-2.

${ }^{18}$ The paper also subscribes to the precautionary and polluter pays principles of environmental policy, and argues that responsibility towards the environment grows in tandem with economic wealth, income, and development. However, because the debates on SD are highly complex and involve fundamental value considerations, there are a number of dimensions that fall outside the scope of this paper. These include the "avoidability of unsustainability," as well as important normative questions like development rights, equity, and fairness. The complexity of the question of how much non-renewable natural resource consumption and pollution is reasonably avoidable, particularly on a per capita basis, becomes extremely apparent in the Gulf monarchies, which have large fossil fuel export industries, small populations, high GDP per capita levels, scarce natural water resources, and a hot climate. The right to socioeconomic development of developing countries is also an extremely difficult one, particularly in the case of the GCC where welfare levels among a large part of the population are high, but knowledge economy and institutional development are still under way. Still, it could be argued that economic wealth increases any state's responsibility towards its natural resources and environment-even when there is lack of awareness among the general population. Other normative issues on a limited planet are the fair share of per capita consumption and pollution (particularly greenhouse gases).

${ }^{19}$ Susan Baker, Sustainable Development, 26.

${ }^{20}$ On environmental security, see the works of Dabelko, Gleick, Homer-Dixon, and the UNEP. For natural security, see Sharon Burke, "Natural Security," Working Paper, Washington D.C.: Center for a New American Security, 2009.
} 
is not seen as requiring economic growth, which can even be detrimental to it. It requires a sustainable economy, defined by Daly as one that accepts the biophysical limits of our planet, enabling it to operate far into the future. ${ }^{21}$

The interlinked notions of limited resources and ecological carrying capacity are important for this study. In a similar manner that there is only a limited amount of exploitable fossil fuels (to some extent dependent on technological development), there are also limits to how much groundwater can be sustainably abstracted and how much greenhouse gases the atmosphere can safely absorb. Land and marine ecosystems, including fish stocks, have boundaries and thresholds, as does climate change. ${ }^{22}$ Technologies, like desalination or carbon capture and storage, can potentially extend these limits, and government interventions in the market, such as gasoline or utility subsidies, can temporarily hide these limits. In most cases, however, the price of growth in consumption will have to be paid for in the future in the form of rising production costs due to depletion of natural water sources; biodiversity losses; marine and air pollution; unexpected negative consequences, such as leakage of $\mathrm{CO}_{2}$; and, with high probability, rising temperatures and sea levels. Some limits are more bound to national borders, like water, waste, and ecosystems; others are transboundary, like climate change, or manipulated through trade, like energy and food.

\section{Measuring Natural Unsustainability}

A number of quantified indicators demonstrate the natural unsustainability of the contemporary Gulf monarchies: the economic opportunity cost and environmental impacts of domestic energy and desalinated water consumption are massive in all six states and are expected to grow further. Saudi Arabia, for example, currently consumes domestically over a fourth of its oil production $(2.8$ million $\mathrm{bbl} / \mathrm{d}) .{ }^{23}$ Due to free or near-free provision, the Qatari government recovers less than a third of the cost of water production. ${ }^{24}$ Oil and gas industries are heavy polluters: in Qatar and Abu Dhabi, they produce half of the monarchies' total $\mathrm{CO}_{2}$ emissions and lift the states to among the world's highest emitters per capita. ${ }^{25}$ Agriculture is depleting the countries' scarce groundwater resources. In Qatar, where depletion is happening at a rate of $500 \%$, the sector generates less than $10 \%$ of domestic food consumption and

\footnotetext{
${ }^{21}$ Herman A. Daly, "Economics in a Full World," Scientific American 293 (September 2005). For a parallel discussion on natural sustainability, see the author's forthcoming book: The Gulf Monarchies and Climate Change: Abu Dhabi and Qatar in an Era of Natural Unsustainability (London: Hurst, 2012).

${ }^{22}$ On planetary boundaries see, for examplem, Johan Rockström et al., "Planetary Boundaries: Exploring the Safe Operating Space for Humanity," Ecology and Society 14 (2009).

${ }^{23}$ Glada Lahn and Paul Stevens, Burning to Keep Cool: The Hidden Energy Crisis in Saudi Arabia (London: Chatham House, 2011), 2.

${ }^{24}$ General Secretariat for Development Planning (GSDP), Qatar National Development Strategy 2011-2016 (Doha: GSDP, 2012), 218.

${ }^{25}$ Abu Dhabi: author's calculations; Ministry of Environment of Qatar, Initial National Communication to the UNFCCC (Doha: Government of Qatar, 2011).
} 
less than $1 \%$ of GDP. ${ }^{26}$ Despite wide national income disparities, the GCC states' per capita demand on the Earth's resources is formidable: Qatar, Kuwait, and the United Arab Emirates (UAE) currently have the world's largest ecological footprints. Notably, the footprint indicator evaluates consumption within a country's borders, excluding exports but including imports, thus eliminating the "unfair" impact of the Gulf states' export industries. ${ }^{27}$

More than anywhere else in the Gulf, Qatar, with its natural gas abundance and the world's third largest proven natural gas reserves, is artificially extending the limits of the local ecological carrying capacity. Due to this abundance, Qatar's present natural resource use can easily be mistaken as sustainable and within carrying capacity because supply comfortably meets demand of the current and near-term future population and industries. However, in reality, it fails to meet even the most basic economic or environmental sustainability criteria, as described above. Furthermore, due to the natural gas-enabled "illusion of abundance," going beyond tipping points might be concealed at first, allowing for even greater damage and degradation of resources.

What then produces natural unsustainability in the Gulf monarchies? Discussed at length in a forthcoming book by the author, ${ }^{28}$ the short answer is: the GCC states' multifaceted dependence on fossil fuels. The current state of imbalance was created by the economic and population boom of the 2000s, and the skyrocketing electricity and water demand. Fast modernization and, in most cases, small national population size have also contributed to the imbalance. Natural unsustainability in the Gulf states has three structural factors: the persistently strong rentier elements of the political economies; ${ }^{29}$ continuing authoritarianism of the political systems; and the social contracts in which these two coalesce. A central concept is the illusion of abundance, which the GCC social contacts have given rise to. Its symptoms include high and wasteful energy and water consumption patterns and general disregard for environmental sustainability. Low levels of environmental awareness are also typical, and the use of economic instruments to influence behavior is complicated by, on the one hand, the centrality and longevity of high utility and fuel subsidies in the social contracts and, on the other, high income levels among the heaviest users, which easily render this mechanism unfair and less effective. Institutional youth and low human capacity are other characteristics that add to the problem; implementing the often ambitious development plans-devised generally in newer and more dynamic government agencies-is hindered by inertia in

\footnotetext{
${ }^{26}$ GDSP, Strategy, 81; Qatar National Food Security Programme, http://www.qnfsp.gov.qa/; Ali Hamed Al Mulla, "Chapter 4: Climate Change and Human Development in Qatar: Issues, Challenges and Opportunities," unpublished, drafted for Qatar's Second Human Development Report, 2009.

27 See Appendix 1.

${ }^{28}$ See Luomi, Monarchies and Climate Change.

${ }^{29}$ See Hazem Beblawi and Giacomo Luciani, eds., The Rentier State (New York: Croom Helm, 1987).
} 
decision-taking and lack of coordination among other public sector institutions, which are often larger and more bureaucratic.

A central question of the sustainability debate is: how to reverse this trend? According to the Limits to Growth authors, there are three complementary drivers of sustainability that are also valid for natural sustainability: technological, cultural, and institutional change. ${ }^{30}$ Those who emphasize system limits recognize the important role of technology, but call for urgent reforms in the two latter areas. ${ }^{31}$ They consider the involvement of people through top-down and bottom-up awareness-raising as crucial for the ultimate goal of bringing consumption and behavioral patterns back to naturally sustainable levels. Given the absence of independent and organized environmental groups in the GCC states, these governments have in the recent years begun realizing the imperative to take the lead in raising awareness, with the UAE spearheading the trend. ${ }^{32}$ Institutional change is equally important. There are currently significant institutional shortcomings in capacity, culture, coordination, and outcomes, which ultimately relate to human capacity and values, and therefore require time to change. The GCC states have only just begun working in these two areas, and it is therefore in many cases too early to judge. Still, the major concern is that the pace of positive change in the three areas (technology, values, and institutions) is not likely to catch up with the accelerating growth and its negative impacts. A revision of current development priorities is required.

\section{Natural Sustainability in Qatar's Development Planning}

\section{Planning Documents}

In the late 2000s there was a GCC-wide trend of long-term planning aimed at boosting economic diversification and job creation, ${ }^{33}$ which, in some cases, was accompanied by a measure of public sector reform. In Qatar, this has taken the form of two major documents produced by a newly formed and dynamic planning agency, the General Secretariat for Development Planning (GSDP). The Qatar National Vision 2030 (QNV), launched in 2008, describes the government's long-term objectives. By establishing general policy and development priorities, the QNV has in many ways been an accelerator for action and has provided a clear sense of direction for both government(-sponsored) and private entities, which often refer to its principles either to support existing campaigns/projects or to guide planning/establishment of new

\footnotetext{
${ }^{30}$ Meadows et al., Limits to Growth, x.

${ }^{31}$ See, for example, Dennis Pirages, "From Limits to Growth to Ecological Security," in Scarcity, 18.

${ }^{32}$ See, for example, the "Heroes of the UAE" campaign and the work of the Environment Agency-Abu Dhabi in general.

${ }^{33}$ Martin Hvidt, "Economic and Institutional Reforms in the Arab Gulf Countries," Middle East Journal 65 (Winter 2011): 88.
} 
ones. ${ }^{34}$ As an operationalization of the QNV, government agency-led task teams produced 14 sector-specific, short-term planning strategies and reports. The GSDP compiled these into a single 270-page document titled, The Qatar National Development Strategy 2011-2016 (NDS), launched in 2012. In order to increase ownership by stakeholder institutions and citizens, the preparation processes of both documents included consultations with representatives from all sectors of society-four of whom contributed to this study. Other methods used in the NDS drafting process included situational analyses and regional and international benchmarking. ${ }^{35}$

The QNV subscribes to the general Brundtland definition of SD in stating that "Qatar will meet the needs of this generation without compromising the needs of future generations." This will be carried out by "balancing the needs of economic growth and social development with the conditions for environmental protection." Both planning documents are structured by a four-pillar division into: human, social, economic, and environmental development. They also enshrine the values and concepts of intergenerational justice and managed growth, and emphasize the responsible use of resources. ${ }^{36}$

With regards to hierarchy, the documents are aligned with the weak notion of $\mathrm{SD}$, declaring that "economic development and protection of the environment are two demands neither of which should be sacrificed for the sake of the other." A step towards prioritizing the economy over the environment is nevertheless taken by stating that "a development pattern based on the energy industry means that some environmental impacts are inevitable." ${ }^{37}$ Only two of the 20 key medium-term national challenges identified in the NDS address natural sustainability challenges: unsustainability of water consumption patterns and environmental stresses of urbanization and consumption patterns. The strategy mentions a further goal of enhancing efficiency of resource use, but with the aim of supporting high standards of living exclusively. ${ }^{38}$ Not coincidentally, environmental development figures as the last of the four pillars in both documents.

\footnotetext{
${ }^{34}$ Examples in rhetorical support abound: Msheireb Properties, the FIFA World Cup projects, RasGas and other oil and gas sector companies, GreenGulf and Qatar Solar Technologies, several universities, and the developers Barwa and Qatari Diar, among others.

${ }^{35}$ GSDP, Strategy, 3. Another important document, the Qatar National Master Plan, which has been under preparation for several years, was still awaiting Emiri approval at the time of writing. The Master Plan will include detailed long-term plans for urban planning (including infrastructure, zoning, and land-use) and public transport, and takes environmental sustainability into account in a holistic manner. However, given that the Master Plan has not been made public, developments in this area (and in particular those that fall outside the scope of the five-year development strategy, i.e. 2017 onwards) are therefore excluded from the scope of this paper. However, due to the profound natural sustainability impacts - both positive and negative - that building the infrastructure needed for hosting the 2022 FIFA World Cup is expected to create, an analysis on this topic will be important and pertinent, once plans start shaping up in some more detail.

${ }^{36}$ GSDP, Vision, 1-9; GSDP, Strategy, iii.

${ }^{37}$ GSDP, Vision, 8; GSDP, Strategy, 35.

${ }^{38}$ This view is also established in the QNV; GSDP, Strategy, 26; GSDP, Vision, 24.
} 
While the documents do not explicitly confirm their stance on the substitutability of natural resources and ecosystem services, statements like the following one confirm a belief in the possibility of direct trade-offs: "environmental degradation can be reduced [and should be compensated] through investment in advanced technologies." This understanding is also implicit in the QNV, which highlights the SD benefits of converting natural capital, specifically hydrocarbon resources, into financial wealth, and further into human-made capital. ${ }^{39}$ The NDS emphasizes the need to replace hydrocarbon income with alternative sources of income and to expand Qatar's productive base by investing in physical and social infrastructure. ${ }^{40}$

Both documents mention all three drivers of SD/natural sustainability. The environmental management strategy envisions "a broad shift in laws, regulations, management systems, technologies and attitudes." ${ }^{\prime 11}$ The greatest emphasis arguably lies in technology and efficiency gains, particularly in the water and energy sectors. ${ }^{42} \mathrm{With}$ regards to institutional reform, the NDS stresses the importance of modernization and development of public institutions, and educational reform. However, somewhat contradictorily, but also realizing the magnitude of the task, it defines establishing "sophisticated environmental institutions" as a "longer term" goal. ${ }^{43}$ Both plans also stress the need to educate people about the environmental externalities of resource consumption and instill "a sense of shared responsibility towards the environment," but arguably fall short of pledging tangible action to achieve this. Adhering to a stronger SD vocabulary, the NDS refers to the need to make citizens understand "what is at stake" and "what they and their families have to gain" from the "paradigm shift" to sustainable environmental management and intergenerational equity. ${ }^{44}$

Finally, with regards to system limits, the plans give their full support to the growth paradigm, with only a few boundary conditions: growth must be managed, controlled, balanced, and sustainable..$^{45}$ It must produce real economic expansion and secure a high standard of living, and it should be balanced with the social and environmental pillars of SD. ${ }^{46}$ The NDS claims to be the first plan that "explicitly aligns the growth of national prosperity to the realities of environmental constraints." Nevertheless, for preventing environmental degradation, the QNV prescribes advanced technologies and "avoiding rapid and unplanned growth," rather than directly acting to curb existing consumption and pollution patterns. ${ }^{47}$

\footnotetext{
${ }^{39}$ GSDP, Vision, 8 and 24.

${ }^{40}$ GSDP, Strategy, 7.

${ }^{41}$ GSDP, Vision, 32; GSDP, Strategy, 23.

${ }^{42}$ GSDP, Strategy, 9, 83, ch 6.

${ }^{43}$ GSDP, Strategy, iii, 232, and 236.

${ }^{44}$ GSDP, Strategy, 40 and 236.

${ }^{45}$ GSDP, Vision, 3; GSDP, Strategy, iii.

${ }^{46}$ GSDP, Vision, 6, 27, and 30; GSDP, Strategy, 215.

${ }^{47}$ GSDP, Strategy, 215; GSDP, Vision, 8.
} 


\section{Green Stakeholders'Views}

Stakeholder views on the nature of sustainable development were charted by asking them to evaluate the feasibility of two statements from the QNV that reflect the triple bottom line approach to SD. Many agreed that the three-pillar approach defines the ideal relationship between the economy, the environment, and development, which is also achievable in the presence of compliance and well-framed, integrated policy frameworks.

Variation emerged in the participants' views regarding the practical feasibility of the proposition not to sacrifice economic development and environmental protection in Qatar at the expense of each other. Responses ranged from generally optimistic to strictly negative. A renewables expert saw the possibility of win-win reconciliation, noting that addressing Qatar's water imbalance and $\mathrm{CO}_{2}$ emissions places little burden on the industries and can create savings through efficiency and cuts in wastage or can even drive economic and industrial activity. A planning expert pointed out that the economy and environment are at loggerheads worldwide, but that thanks to recent global improvements, Qatar now has "a great opportunity to deploy the world's best practices" in SD. In addition, an ecology expert noted that aiming at SD requires environmental protection and "better choices in economic development," which so far has been pursued at the expense of the environment: "... I know of no example where the environment has been put first."

Another academic saw economic growth and environmental protection as fundamentally incompatible, as the latter "implies at least a steady state, or decreased use of natural resources." In the absence of a "great shift in mentality and practice," the environment will continue to be sacrificed for the economy, a sustainability expert argued. Further, a planning professional pointed out that despite short-term negative economic impacts, a greater emphasis on the environmental pillar would have longlasting benefits for future generations and for economic sustainability. In general, many of the stakeholders shared a concern over the prioritization of economic growth and development over the environment, which was in contrast to the optimistic tone of the government's planning documents.

\section{Problems and Challenges of Natural Unsustainability}

The five-year NDS identifies Qatar's main SD challenges and problems and sets a number of descriptive and quantifiable targets up until 2016. It addresses issues relating to natural sustainability in two chapters: Sustaining Economic Prosperity (economy), and Sustaining the Environment for Future Generations (environment), which summarize the respective sector strategies. With regards to the economy 
chapter, the focus of this study is limited to the areas of water and energy. ${ }^{48}$ Strategy work in this area was led by Qatar Petroleum. The entire environment chapter, which is based on work led by the Ministry of Environment and the GSDP, is included in the examination. For this part of the study, the green stakeholders were asked whether and how they thought natural resource use in Qatar was currently (un)sustainable, especially in relation to the environment. Another set of questions was concerned with the experts' views on the attainability and sufficiency of the targets set in the NDS. These will be addressed later in the paper.

\section{The Problem as Defined by the Qatar National Development Strategy}

The economy chapter of the NDS defines Qatar's challenges in natural resource consumption through the lenses of technical, economic, and market efficiency. It stresses the issue particularly in the context of economic gains, but also recognizes related fiscal benefits and resulting reductions in waste and pollution. The environment chapter takes a distinguishably more limits-oriented approach, which also considers the demand side of the equation and recognizes the role of people and institutions in driving sustainability. It lists five key environmental stress points: water tables, groundwater salinity, air quality, climate change, and biodiversity. ${ }^{49}$

"Few tangible aspects of Qatar's life and economy need efficiency reforms as much as water," the NDS notes. ${ }^{50}$ While all sources (desalinated, recycled, and groundwater) suffer from inefficiencies, desalination is regarded as the most challenging: by 2020, demand is expected to rise by $5-7 \%$ per year, driven by population growth, distribution losses, and higher household use. However, existing technologies place limitations on production, and expansion beyond the current capacity of 539 million $\mathrm{m}^{3} / \mathrm{year}$ is deemed to be difficult, which is strictly at odds with plans to enhance national food security through a massive, solar desalination-enabled domestic agricultural expansion program. Due to the high dependence on desalination, water will pose both security and financial challenges: limited storage capacity (1.5 days); costly production process (co-generation of water and electricity); coastal land and seawater quality requirements; escalating demand (tripling between 1995 and 2008); and, most importantly, high distribution losses costing up to QR1bn/year. ${ }^{51}$

\footnotetext{
${ }^{48}$ Land use, agriculture, and fishing are excluded because of a need to narrow the scope of the analysis. The task team on Natural Resource Management, led by Qatar Petroleum, produced a synonymous sector strategy. The task team on Environmental Sustainability, led by the Ministry of Environment, produced together with the GSDP the Environmental Sector Strategy. GSDP, Strategy, xi and xiii. Neither strategy had been made public at the time of writing.

${ }^{49}$ GSDP, Strategy, 80-1 and 214-5.

${ }^{50}$ Ibid., $81-2$

${ }^{51}$ Ibid., 218; OECD system losses are said to be $18 \%$ on average.
} 
Withdrawals of Qatar's extremely scarce reserves of groundwater, used predominantly for inefficient (flood) irrigation, are five times the recharge rates, and wastage is exacerbated due to lack of pricing. Deteriorating quality is also described as a growing concern, as certain agricultural discharges increase groundwater (and soil) salinity. Only a fourth of wastewater is recycled-a figure that still compares favorably with the Gulf average of $16 \%$. A great share of the rest goes untreated into septic lagoons, and undeclared quantities continue to be dumped into the sea without treatment. Furthermore, although four times less costly than desalination, only $60 \%$ of treated effluent is utilized. Infrastructure too poses challenges: Doha's water table is rising as a result of distribution losses at ca. 30 million $\mathrm{m}^{3} / \mathrm{year}$ and leakages from the sewage networks at 20 million $\mathrm{m}^{3} / \mathrm{year}$. This presents health hazards to the population and additional costs for the construction industry. The strategy carefully notes that the current practice of pumping this water into the sea "may be harming the marine environment." The economy chapter attributes Qatar's extremely high per capita consumption levels largely to agricultural use patterns and technical and economic inefficiencies, whereas the environment chapter attributes much greater importance to awareness and behavior. ${ }^{52}$

The NDS recognizes that, despite Qatar's robust domestic energy security situation, the opportunity cost of domestic power production is high. It also notes that certainty of supply and lower greenhouse gas emissions are additional gains from increased energy efficiency. Air-conditioning currently uses close to $70 \%$ of residential power consumption, and the NDS sees potential in energy-efficient AC units and other appliances as well as in technologies, such as district cooling, and more efficient building-codes. Efficiency gains are also envisaged through production infrastructure upgrades and dispatch strategies. The strategy estimates the potential for technical savings at $5 \%$ of domestic gas consumption, but does not elaborate on how much could be saved through conservation measures in the domestic sector. Notably, indicating low interest in alternatives at the time of drafting, the NDS dismisses renewable energy as something that is not yet cost-efficient for Qatar and remains silent on nuclear power. ${ }^{53}$

The environment chapter in the NDS notes the health risks related to the rapid rise of greenhouse emissions and pollution from industries over the past decade. It does, however, defend Qatar's high per capita $\mathrm{CO}_{2}$ emissions by referring to the large share of industrial consumption of total emissions (67\% in 2007), and highlights the significant cuts in gas flaring already made. The most important one of these is

\footnotetext{
${ }_{52}^{5 S D P}$, Strategy, 81-3 and 219-20. The economy chapter too sees some space for improvement in consumption patterns among residential and commercial users. Although the NDS (p. 220) estimates leakage in transmissions at 100 million $\mathrm{m}^{3} /$ year, newer figures from Kahramaa (personal correspondence, June 2012) reveal that this figure (which was 80 million $\mathrm{m}^{3}$ in 2011) includes also "apparent losses" (i.e. metering inaccuracies), leading to real leakages only constituting 32 million $\mathrm{m}^{3}$ that year.

${ }^{53}$ GSDP, Strategy, 10 and 84-5.
} 
the massive Al-Shaheen project, which, since 2007, has avoided $2.5 \mathrm{Mt} / \mathrm{CO}_{2} \mathrm{e} / \mathrm{year} .{ }^{54}$ On the adaptation side of climate change, the environment chapter notes Qatar's vulnerability to sea-level rise and weather events, and potential threats to food security, among other issues. ${ }^{55}$

Regarding market inefficiencies, the strategy mentions the free access to groundwater for local farmers and, in most cases, free power and water for Qatari citizens who currently consume, on a per capita basis, seven times as much water as non-citizens. The utility price subsidies are seen to clash "with the aspirations of $Q N V$ 2030 and Qatar's sustainability objectives:" they contribute to overconsumption, waste, and low awareness about the wider impacts of consumer behavior. ${ }^{56}$ Inefficiencies in regulation are also mentioned: the absence of a single independent water regulator contributes to inefficient use, and self-monitoring by the existing "operator-regulators" leads to lower service quality. Moreover, there is no agency responsible for water policy in Qatar, and the legal framework is fragmented. ${ }^{57}$

The NDS defines waste management as another key challenge: 7,000 tonnes of solid waste are created daily in Qatar (4.1 kg/per capita), of which $30 \%$ is domestic waste and only $8 \%$ is recycled. Data on hazardous waste is disorganized, and hence a true concern. ${ }^{58}$ Land and marine biodiversity is threatened by population and urban growth, construction activities, industrialization, international shipping, overfishing, overgrazing, and climate change, and there are important shortcomings in data and monitoring. ${ }^{59}$

The strategy stresses that the current wasteful consumption patterns of energy and water need to be "better managed" for the sake of intergenerational justice. Not directly admitting that environmental awareness is low, it suggests that "Qatar harbours an environmental consciousness that can be strengthened and expanded." It admits that "knowledge development" to enable a better management of scarcity "has not kept pace with the country's unprecedented... growth." ${ }^{60}$ It recognizes human and institutional capacity limitations as major challenges in the implementation of plans. In the area of environmental governance, the NDS notes that capacity-building and more scientific professionals are needed to enable the Ministry of Environment, established in 2008 , to "fully monitor the environmental impact of a rapidly expanding economy."

\footnotetext{
${ }^{54}$ UNFCCC CDM, http://cdm.unfccc.int. Project 0763. For comparison, in 2007, Qatar flared 8.5 Mt/CO e. Ministry of Environment of Qatar, Initial Communication, 40.

${ }^{55}$ GSDP, Strategy, 221-4.

${ }^{56}$ Ibid., 88 and 218.

${ }^{57}$ Ibid., $91-2$ and 220.

${ }^{58}$ Ibid., 224-6; Waste per capita calculated by the author, based on a population of 1.7 million.

${ }^{59}$ GSDP, Stratgey, 226-8.

${ }^{60}$ Ibid., 229-30 and 232-4; Somewhat strangely, the NDS laments the absence of internationally accepted indexes for environmental progress. For example, the Universities of Yale and Columbia, and the conservation organisation WWF have put forward widely used indicators and criteria. See Appendix 1.
} 
It also implies that the existing institutional goals and division of responsibilities are ambiguous, that decision-making lacks integration, and that both cross-sectoral coordination and information-sharing are faltering in many ways: environmental impact assessments, for example, are not made publicly available. ${ }^{61}$

\section{The Problem as Defined by the Stakeholders}

The green stakeholders were asked whether they thought that natural resource use in Qatar was sustainable and/or environmentally sustainable. With the exception of one respondent, all those interviewed replied negatively, to varying degrees, which appears to be a direct reflection of the profile of the experts chosen for the study. To make the exercise more constructive, they were also asked to describe the key "unsustainablilities" and related challenges and problems, particularly with regards to water, energy, and land.

In terms of cited examples in the questionnaires, water emerged as the number one victim of unsustainable use. Respondents highlighted two broader issues. The first is aquifer depletion due to uncontrolled agricultural use, inefficient irrigation techniques, and use of arable land; and the second is the squandering of potable, desalinated water in wasteful irrigation and washing cars and streets. Other problems mentioned include high per capita consumption and network leakages, low utilization rates of sewage effluent, and high dependence on desalinated water. Wasteful and high per capita consumption of energy and other resources were also mentioned by the stakeholders, as well as under-exploitation of significant quantities of waste heat from Qatar's two industrial cities Ras Laffan and Mesaieed.

Several stakeholders commented on the economic pillar of SD, noting that despite the fact that Qatar has sufficient quantities of natural gas to cover all its future power and desalination needs, the current excessive economic dependence on hydrocarbons is overall not sustainable. Referring to the weak/strong SD discussion, an ecology expert noted that judged by even weak sustainability criteria, non-renewable resource use in Qatar is not sustainable because all profits gained from it are not invested in types of resources that can sustain the country. ${ }^{62}$ Here, subsidies are the cause: "we need to be paying full price for a resource so that money can be invested for future generations," according to the expert.

A great majority of the respondents mentioned price subsidies and lack of consumer awareness as the main drivers of unsustainable consumption patterns. As a biodiversity expert expressed it: "subsidies are killing any sustainability efforts." Many

\footnotetext{
${ }^{61}$ The strategy also calls for regional cooperation, given the shared and transboundary character of many natural resource and environmental challenges; GSDP, Strategy, 23-6, 230-1, and 234.

${ }^{62}$ See the first section of this paper for a discussion on the Hartwick rule.
} 
pointed out the direct link between excessive energy and water use and the absence of market mechanisms: highly subsidized or free utilities abolish the feedback link that in many countries exists between consumption and cost, thus removing any incentive to limit resource use. Political considerations and perceptions on the existing social contract in Qatar play an important role in perpetuating the pricing regime: "being a rentier state has an impact on how far the government can moderate the use of natural resources," a water expert noted. Low awareness, in turn, was attributed to a lack of education and weak awareness campaigns.

Alongside population growth, the respondents saw economic wealth as a major driver of unsustainable, excessive consumption. This arguably intertwines with the region's rapid modernization and perhaps with cultural values too, which have arguably been affected by related societal changes and the vast and fast influx of wealth. An urbanism expert lamented how "within the built environment, there is an inherent conflict between luxury and sustainability." Examples of expectations embedded in ideals of luxury in relation to infrastructure in Qatar include high flow showers, temperature-controlled swimming pools, and office spaces air-conditioned at $22^{\circ} \mathrm{C} .{ }^{63} \mathrm{~A}$ sustainability expert pointed out a dilemma in the impact of pricing: even if political obstacles were overcome and prices were raised, high-income segments of the population would still be able to keep consuming as usual.

Regarding other sectors, some stakeholders noted that lack of regulation, enforcement, and best practices are driving unsustainable consumption patterns in the industrial and agricultural sectors. There were concerns of insufficient awarenessraising and enforcement of recent policies to limit grazing and protect areas currently designated as natural reserves, comprising $22-27 \%$ of Qatar's territory. ${ }^{64}$ Further, a planning expert thought that businesses are often "driven by profit and greed" and lack incentives to act responsibly. In the construction industry, the limited regional availability of materials creates a barrier to sustainability. The respondents also described the government as short-term goal-oriented. Environmental management was cited as a further GCC-wide challenge: mechanisms are being developed, but they remain uncoordinated. A dearth of specialists is also an issue.

The green stakeholders raised two broad categories of negative environmental impacts: pollution and emissions, and land use and biodiversity issues. Qatar's high per capita hydrocarbon use and $\mathrm{CO}_{2}$ emissions were labelled as unsustainable on a global level and "contributing disproportionately to climate change." Desalination has negative impacts on the marine environment and produces greenhouse gas emissions.

\footnotetext{
${ }^{63}$ The author has registered a low of $15^{\circ} \mathrm{C}$ in some buildings in Doha.

${ }^{64}$ GSDP, Advancing Sustainable Development: Qatar National Vision 2030. Second Human Development Report (Doha: 2009), 20; Qatar Statistics Authority, Qatar Social Trends 1998-2010 (Doha: 2011), 30.
} 
The deteriorating quality of groundwater reserves due to saltwater intrusion and salinization of soil due to excessive irrigation were also raised by the respondents. The yet unknown impacts of industrial pollutants and industrial cooling waters, which include chlorine, on the fragile desert and marine ecosystems, were a concern for two environmental experts. Underground water reserve depletion and overall biodiversity loss were cited by a number of stakeholders. While the former is a single-sector problem, the latter has a number of causes: recreational use, urbanization, development of coastal lands, and overgrazing. Alongside the "tragedy of the commons" 65 unfolding around fisheries, which has a direct impact on food security, threatened and suffering species include mangroves, sea grass, sea turtles, and dugongs.

The planning documents and stakeholders share a number of common concerns. However, the major differences are in the stronger emphasis placed by the green experts on natural water reserve depletion and the importance of changing behavior rather than increasing efficiency and providing technological solutions.

\section{Combatting Natural Unsustainability}

\section{Problem Solving as Defined by the National Development Strategy}

In order to address the challenges and problems identified in the NDS process, the respective sectoral documents propose a number of qualitative and quantitative targets. The target-oriented planning model applied in the strategy originates from an outcome-based approach to strategic planning advocated by the GSDP across all sectors. ${ }^{66}$ The following section discusses the targets set for natural resource efficiency in energy and water as described in the economy chapter of the NDS and those for environmental management outlined in the environment chapter. Below, the actions are classified along four normative dichotomies: numeric-qualitative; measurableambiguous; ambitious-inadequate; and dependent on government/public sector action exclusively-involving the broader society. Notably, the NDS includes a great number of recommendations, conditionalities ("can," "could," "would," "should”), aspirational statements, and other vague expressions ("will look into," "will study," etc.), which are excluded from this analysis.

In the area of natural resource efficiency overall, few of the set targets are measurable and only two involve engaging the society as a whole. Furthermore, the only numeric and markedly ambitious target is cutting network losses of desalinated water to $10 \%$ (from $30-35 \%$ a few years ago and $21 \%$ in 2011), through sealing leakages

\footnotetext{
${ }^{65}$ Garrett Hardin, "The Tragedy of the Commons," Science 162 (December 1968): 1243-48.

${ }^{66}$ GSDP, Strategy, 25.
} 
(equal to $40 \%$ of total losses in 2011) and other measures. ${ }^{67}$ Even in this case, it seems that most of this target will be reached through revising calculations and fixing water meters and other related inaccuracies. Other targets for water and energy, ${ }^{68}$ most of which are led by the state utility company Kahramaa, include installing water meters and water and energy-saving technologies; increasing the use of recycled water; and improving thermal efficiency power production. There are a number of institutional and regulatory measures, the most important of which is establishing an independent utility regulator.

Notably, as a market efficiency target, the strategy sets to phase in higher utility and fuel prices. Giving few details, it only mentions that communication and technical efficiency measures should precede higher charges. It also proposes exempting Qatari nationals from charges up to a certain level or using direct income transfers as a compensatory mechanism. Presumably stemming from perceptions regarding the political sensitivities and security dimensions of the agricultural sector-as well as the ongoing work of the National Food Security Programme-, no tangible measures are established for tackling groundwater depletion in the coming years. ${ }^{69}$

The environmental management strategy addresses a wider variety of sectors and envisages a parallel shift involving all three drivers. ${ }^{70}$ Many of the set targets are measurable. Perhaps the most salient is the goal to halve the intensity of gas flaringwhich in 2007 constituted 12\% of emissions - in energy production between 2008 and 2016. Cutting these emissions, as noted, is politically uncontroversial and economically advantageous. ${ }^{71}$ Presumably, the goal will be largely achieved through a massive US $\$ 1$ bn gas recovery project at tanker berths in Ras Laffan and the overall increase in energy production. ${ }^{72}$ Other tangible targets are: enacting a National Water Act; establishing a solid waste plan, containing current per capita waste levels, and recycling 38\% of solid waste (up from 8\%); establishing biodiversity and environmental information databases; creating three green urban corridors; and leading one regional environmental effort and two joint projects with the private sector. Less tangible institutional targets are: improving the management of air quality and protected areas - as no actively managed areas currently exist-, and monitoring groundwater. ${ }^{73}$ Eliminating excess water from Doha's water table and conserving groundwater are also mentioned. With regards to

\footnotetext{
${ }^{67}$ According to the head of Kahramaa's Water Control Centre (Twitter communication on May 24, 2012), network losses are currently at $19 \%$. It remained unclear whether this was due to new information or to new measures taken.

${ }^{68}$ See Table 2 in Appendix 3.

${ }^{69}$ GSDP, Strategy, 84-5, 89 and 92; personal correspondence with Kahramaa, June 2012.

${ }^{70}$ GSDP, Strategy, 23; see Table 3 in Appendix 3.

${ }^{71}$ GSDP, Strategy, 224.

${ }^{72}$ The project will eventually recover 0.6 Mt of LNG per year. Qatargas, Pioneer (August 2011): 4.

${ }^{73}$ As noted by one of the stakeholders interviewed.
} 
waste, most of the recycling goal (20-25\%) will be reached without source separation by consumers in a solid waste management center that opened in the industrial city of Mesaieed in 2011. ${ }^{74}$

The most ambitious, yet the most vaguely formulated target is to "build an environmentally aware society," partly with the help of a well-known national role model. An initial move towards this direction was taken in the spring of 2012 with Kahramaa's Tarsheed ("conservation") utility consumption awareness campaign, targeted mainly at nationals and bulk customers. An example of the latter includes the City Center mall complex, which has a consumption that is on par with the entire town of Wakra, south of Doha. ${ }^{75}$ Importantly, the attainment of only two of the targets—awareness and waste management - involves the broader society. Private sector engagement rests on a goal of two joint projects only, and industry-related goals only concern government-owned companies. Water being defined as a primary area of action, emphasis is placed on the laudable effort to establish a comprehensive policy, the Water Act, and a system of integrated regulation, including quality standards, conservation incentives, and discharge management. Plans are also to increase interinstitutional dialogue on environmental governance through staff exchanges. ${ }^{76}$

\section{Stakeholder Evaluation of Attainability and Sufficiency}

The thirteen stakeholders were asked to evaluate the attainability and sufficiency of the targets outlined above. ${ }^{77}$ An overwhelming majority thought that most, if not all, targets are achievable by 2016 or soon after. Political will, some said, exists, and plans to achieve certain targets are already being implemented. However, several preconditions and reservations were mentioned. Technology and financing were not seen to pose a problem but values, or "mind set and cultural bad practices," were regarded as hindrances by some of the respondents. Conditions for achieving the targets mentioned were: awareness, education, comprehensive involvement of all sectors in the relevant initiatives, evaluation and monitoring, strong enforcement, and moving from "talking" to implementation. The lack of measurability in many targets was said to provide an easy route to ticking the boxes, as were per capita targets, which benefit from the low consumption levels of migrant workers. A biodiversity expert was sceptical about achieving high levels of awareness, given the absence of role models and few ways to challenge existing unsustainable behavioral patterns. Also, an ecology expert predicted resistance to metering residential water due to the prevailing perception among

\footnotetext{
${ }^{74}$ GSDP, Strategy, 220-32.

${ }^{75}$ Personal correspondence, May 2012.

${ }^{76}$ GSDP, Strategy, 220-32. Furthermore, there are plans for increasing storage and production capacity, which remain beyond the scope of this paper.

${ }^{77}$ Two other goals (utility charges and independent regulator) were not included in the questionnaire.
} 
the local community of subsidies as wealth redistribution. An urbanism expert also lamented the lack of "a concerted effort to institute recycling" at the residential level.

The green stakeholders were also asked to propose additional measures to raise ambition and to sufficiently address Qatar's major natural sustainability challenges. When asked to evaluate the natural resource strategy alone, most respondents strongly criticized the lack of attention on the demand side of the equation, particularly consumer behavior, and called for more attention to education and raising awareness. Even awareness-raising efforts of the environmental strategy were deemed to be insufficient by some. One expert saw awareness-raising among secondary and lower management levels as particularly important. The environmental targets were criticized overall for being insufficient in affecting choices in the business sector, particularly with regards to land use. Attention to enhanced communication between government entities was also said to be missing.

Other proposed additional measures included: targets for renewable energy and water, and energy use reduction; tougher reporting requirements, regulation, and enforcement, especially in the construction and industrial sectors, with regards to air pollution; support from the top elite for environmental entrepreneurship opportunities; applying already available environmentally friendly technologies; recharging aquifers; monitoring the long-term impact of desalination on the Gulf; and designing policies that "help people make good choices by providing the right incentives." Measures to address the reliance and heavy use of cars were also called for. Furthermore, despite the goal to cut flaring, a renewables expert said that Qatar is not yet fully playing its part in the global fight against climate change, and called for more attention to related mitigation and adaptation challenges.

\section{Towards Natural Sustainability: Responsibilities, Issues, and Measures}

\section{Responsibility to Act}

Responsibility and equity are two key themes in the debates on SD. There is broad global consensus that poverty reduction is a primary goal and, hence, that developing countries should have the right to (sustainable) development. ${ }^{78}$ Great disagreement, however, remains over what this right entails. Furthermore, the issue of per capita equity remains politically highly contested in the debates on $\mathrm{SD}$, most visible in the negotiations on climate change. Difficult issues regarding international equity include the responsibility of fossil fuel exporting countries over the emissions of their export industries (given that environmental cost has not been internalized in the price earned). In a Gulf domestic context, considerations of equity are arguably important when

\footnotetext{
78 United Nations Conference on Environment and Development, Rio Declaration on Environment and Development, 1992.
} 
discussing demand side measures, such as pricing mechanisms: subsidies should be pro-poor. However, in the GCC, political considerations relating to the existing social contracts between rulers and citizens generally predominate in decisions regarding pricing and access to resources and services, such as transport and land use. As critics have pointed out, the ideology of EM, which is pro-status-quo, "remains silent on issues of social justice, on the distribution of wealth and on society-nature relations." 79 This is, to some extent, true of Qatar's environmental strategy, which largely avoids addressing the issue of consumption and pollution disparities, and only speaks of intergenerational justice.

Responsibility is a parallel debate: who should act first and who should do the most? A government strategy is obviously always more inclined to assign tasks to the government rather than other sectors-as observed in the previous section. However, the most far-reaching changes necessarily involve the broader society. These are also the hardest to achieve because they require action beyond the walls of ministries and state agencies, and might impinge on the popularity of the allocation state or government.

The National Vision talks about responsibility in relation to balancing hydrocarbon exploitation, existing reserves, and the pace of economic diversification. Producing natural gas, labelled as "clean energy," for Qatar and the world is also mentioned..$^{80}$ With regards to the environment, the National Vision assigns the responsibility to balance the three pillars of SD to the state. However, it also includes the following quote attributed to the Emir's wife, Sheikha Moza bint Nasser: "We need to care for our natural environment for it was entrusted to us by God to use with responsibility and respect for the benefit of human kind. If we nurture our environment, it will nurture us." ${ }^{1}$

The NDS recognizes the need for society-wide engagement to enhance environmental management, including "cultivating a sense of environmental responsibility within industry," and notes that awareness-raising will encourage a sense of shared responsibility and develop "positive environmental attitudes and values," such as holding recycling as an "ordinary responsibility." 82 With regards to the private sector, the strategy only discusses the human — and not environmental-dimension of corporate social responsibility. The need to clarify responsibilities among government agencies and ministries is also noted. ${ }^{83}$

\footnotetext{
${ }^{79}$ Baker, "Symbolic Commitment," 116. Equity, however, is a key theme in the educational sector strategy.

${ }^{80}$ GSDP, Vision, 28; the NDS also assigns to the government the responsibility of maximizing the value from exploitation of hydrocarbon assets, but not (explicitly) for minimizing its negative environmental impacts. GSDP, Strategy, 7.

${ }^{81}$ GSDP, Vision, 30.

${ }^{82}$ GSDP, Strategy, 22, 40, 92, 215, 225, 255, and passim.

${ }^{83}$ Ibid., 185-6.
} 
The stakeholders were asked to rank in declining order ( 1 =most, $6=$ least $)$ whom they regard as having the responsibility to initiate change towards environmentally sustainable consumption patterns in Qatar. The government (16 points, of a minimum of 13 and maximum of 78) was overwhelmingly assigned with the highest responsibility whereas expatriates (66 points) were seen as the least responsible. ${ }^{84}$ Qatari nationals (36 points) and industries (37 points) were seen as the second most responsible parties followed by local and international businesses (48 and 50 points).

\section{Identifying the Obstacles}

After defining responsibility, a next logical step is to identify priority areas of action. While this exercise is evident in the national planning documents, as demonstrated above, the underlying emphasis on weak $\mathrm{SD}$, together with the allocation-based political economy and system, shapes the way in which problems are defined and relevant solutions proposed.

The green stakeholders were asked to list the three most important obstacles or challenges for a balance between natural resource use and the environment in Qatar. Strikingly, eleven experts out of thirteen mentioned lack of awareness and education, or behavior of individuals, characterized by a culture of "more, more, more" and a sense of entitlement to natural resources, as the main issues. Responsibility of each individual's actions was also seen to be lacking. Seven stakeholders mentioned shortcomings in governance, most importantly in the areas of regulation and enforcement of laws and policies, and particularly with regards to the industry and land use. A lack of consequence for wasting was also lamented.

Issues pertaining to lack of action, prioritization, and cooperation were raised by five respondents. Political will, serious commitment, and "genuine intention" were said to be lacking. Collaboration among stakeholders and making use of synergies were also seen as frail. The circumstances, or the "hand Qatar has been dealt" regarding the abundance of natural gas and dearth of other natural resources, such as water and food, were also perceived as a major source of obstacles. The existing industrial base and few options for economic diversification were cited to constitute certain insurmountable barriers with regards to energy use and emissions. The rapid pace of infrastructure development and continuing construction with little regard to the environment, and shortage of Qatari professionals specializing in the environment were also mentioned as challenges. Barriers identified elsewhere in the survey included language (particularly with regards to availability of legislation), bureaucracy (leading to non-implementation), access to the Ministry of Environment, and institutional and human capacity.

\footnotetext{
${ }^{84}$ Presumably this result owes to the low sense of empowerment and attachment, and weak channels of participation and influence felt by the expatriate community, among other reasons.
} 


\section{Policy and Management Measures}

If the existing practices are producing natural unsustainability, and if the proposed measures are perceived as: not being enough, not focusing on the right sectors of society, and not using the right instruments, how then to tackle the situation? As in most societal challenges, there is never a silver-bullet solution. Raouf has identified three types of environmental policy instruments: command-and-control, economic, and persuasive. In the past, the GCC states only applied the first approach, and even so, important problems on the enforcement side prevail..$^{85}$ In addition, technological and efficiency improvements can produce positive environmental outcomes. The green stakeholders did not recommend one type of policy measure over others. The questionnaire requested the respondents to rank environmental management measures based on their suitability ( $1=$ most, $6=$ least) for increasing natural sustainability in Qatar over the next decade. Laws and regulation were seen as the most important tools (27 points of a maximum of 78), and market-based disincentives aimed at changing behavior, such as tariffs and taxes, received the second most votes (39 points). Marketbased incentives, such as subsidies, were also preferred (42 points). Technological and efficiency measures (47 and 49 points), and persuasive measures, such as awarenessraising (50 points), were regarded as less suitable tools for increasing natural sustainability in Qatar. This last result seems somewhat perplexing given the strong emphasis that the stakeholders placed on increasing awareness. However, as confirmed by three of the participants responding to a follow-up question, awareness campaigns alone are seen as too soft for raising the level of awareness and changing behaviors given the illusion of abundance surrounding the consumers and the lack of enforced regulation on businesses and industries with regards to their environmental impacts. The transience of Qatar's workforce, which makes up over 85\% of the population and largely originates from countries and social strata where awareness is generally low, such as the Indian subcontinent, was also mentioned as a factor that renders campaigns less efficient.

\section{Conclusion}

There are a number of findings and recommendations, both metal-level and practical, to be deduced from the analysis in this paper. As demonstrated in this study, a weak understanding of sustainable development permeates the development planning of the Qatari government. It is also argued that most of the existing problems and challenges in the area of natural sustainability are symptoms of the underlying growth-oriented worldview, which sets the economy ahead of the environment and believes in broad

\footnotetext{
${ }^{85}$ Mohamed A. Raouf, Economic Instruments as an Environmental Policy Tool: The Case of GCC Countries (Dubai: Gulf Research Center, 2007), 21, 25, and 32.
} 
substitutability of natural capital. The differences in problem definition and problem solving resulting from different understandings of SD were made particularly visible in the comparison between the government's planning documents and stakeholder responses. The latter were more inclined towards stronger interpretations of SD.

The main conclusion, therefore, is unambiguous: for natural sustainability to increase, the standpoint needs to change. But this will require fundamental priorities to change first. Shifts in values take longer than structural transformations, and the rapid, on-going modernization experience of the Gulf monarchies should not be forgotten while demanding change. The adoption of a stronger ecological modernization discourse might be a positive first step for refocusing attention, and is also the most likely direction, as environmental awareness slowly gathers pace in the GCC ${ }^{86}$ However, given the fast pace of economic growth in Qatar in particular, EM discourse alone will be far from sufficient. As has been demonstrated in this paper, adopting a stronger definition of sustainable development would help Qatar and the other GCC states to re-define and propose better tools to tackle some of the existing natural unsustainabilities - something only possible using a limits-focused approach that re-prioritizes the relationship between the economy and environment and places more emphasis on the demand side of consumption.

Qatar's existing development plans are ambitious and undoubtedly grounded in a genuine will to "manage" development. The green stakeholders interviewed for this study believe that the already set targets are achievable if resources and attention are properly directed. Beyond this, however, many of the targets fall short of addressing the respective problems, and there is much room for increased ambition that builds on a fundamental, long-term change in institutions and values. Given the political systems of the GCC and the low general awareness among the national and expatriate populations, change needs to be encouraged from the top, but needs to take place simultaneously at all levels. As a first step, the environmental perspective should be consistently integrated in all natural resource-related decision-making across all government institutions. While this, along with most of the following recommendations, applies for all the GCC states, it is particularly urgent in Qatar, given the relative weakness and narrow mandate of the competent environmental institution. Expressed bluntly, environmental governance should not remain the exclusive domain of HSE departments and should not be reduced to environmental impact assessments and occasional beach clean-ups.

Owing to their political economy and systems, allocation-based social contracts, young institutions, and quick modernization processes, among other reasons, natural unsustainability is currently a built-in characteristic of the GCC states, as international

\footnotetext{
${ }^{86}$ Indicated in 2012, for example, by the UAE's Green Economy Initiative, Abu Dhabi’s Global Green Growth Institute (GGGI), and Qatar's joining in the GGGI founding consortium.
} 
sustainability indicators attest. The positive outcome of this study is to show that change is possible, albeit not easy. By answering the two remaining questions of the study, this paper seeks to contribute to this change by proposing some critical first steps.

It is important to distinguish between the main implications that weaker and stronger views on SD have for definition of problems and solutions and how different understandings regarding the nature of our planet and the relationship between growth and limits influence views on optimal outcomes and futures. Furthermore, listening to views originating from the stronger end of the scale, which have so far been largely lacking in the regional debates on development, provides valuable out-of-the-box ideas for policymakers, planners, and all concerned stakeholders.

The first important lesson relates to institutions. As became evident from the analysis, the Ministry of Environment, the competent environmental institution, embodies a more limits-oriented approach than Qatar Petroleum/Ministry of Energy and Industry, the most powerful energy sector company-institution. The latter's main emphasis lies in technological and efficiency improvements. Problems for natural sustainability arise from the vast disparities between these two in institutional age, clout, funding, and capacity. Qatar's natural gas abundance is also a curse in disguise in that there is little financial or security-related pressure to address the domestic demand side of energy and water.

Since Qatar Petroleum still is, and understands itself, as a fossil fuel company and is deeply entangled with the Ministry of Energy, there has been little room for a discussion on alternatives. ${ }^{87} \mathrm{On}$ the environmental side, the measures were deemed by many of the stakeholders as lacking ambition and weak with regards to the business sector-particularly in relation to land use. Due to Qatar's institutional set-up, the Ministry of Environment cannot propose emission or renewables targets either. These must come from stronger and more influential institutions and must be coordinated. ${ }^{88}$ A related recommendation is to urgently strengthen the mandate and capacity of the Ministry of Environment.

The second important lesson concerns the drivers of SD and related environmental policy tools. As demonstrated above, viewing natural resource consumption through the narrow lens of efficiency leads to overlooking two crucial drivers of sustainable development: institutions and people (i.e. culture and values). In the GCC context, this focus is inseparably linked to the allocation state, which is always reluctant to distribute less to, or demand more from, citizens (and often the general population as well) -

\footnotetext{
${ }^{87}$ As noted, the NDS treats renewables dismissively. Also, Qatar Petroleum has only recently established a small team to monitor and draft a national strategy for renewable energies.

${ }^{88}$ In May 2012, for example, the Qatar Electricity and Water Company mentioned a 10\% target for solar energy in power and water production for 2018, but the ensuing silence and comments by representatives of other entities indicated the goal might be unilateral. Qatar News Agency, "Qatar to Generate 10 Percent Power from Solar Energy," May 22, 2012.
} 
particularly after the onset of the Arab Spring in 2011 as is evident in the recent salary raises or cash hand-outs and delayed utility price reforms in many GCC states. The extension of the social contract into job-provision also complicates institutional change.

Good examples of the misperceptions produced by the efficiency/technology focus are groundwater depletion and the (quantitatively) increasing dependence on desalination. These most certainly are not problems of efficiency, but primarily of growing and excessive consumption due to lack of sufficient enforcement, pricing mechanisms, and awareness. The emphasis on technological fixes and efficiency avoids addressing the demand side, limiting use, or changing habits and behaviors. A further aspect of the importance of human capacity is the fact that technologies are of little use if they are not implemented, adopted, and/or used purposefully.

This does not mean that there is no role for efficiency and technology-on the contrary. Particularly big, low-hanging fruit, such as cutting water network losses and gas flaring in energy production, which also produce immediate and important financial gains, are crucial and noncontroversial first steps. Implementing environmental technologies, standards, and appliances can also make a big difference in Qatar's ecological footprint, but even this will be difficult without proper legislation and its enforcement. Institutional reform in Qatar is ongoing and will need time, but expectations among the green stakeholders are currently much higher than goals proposed in this area, and attention needs to be focused to enforcement of laws and regulations, implementation of policies and plans, and strengthening environmental governance across the board.

Lack of awareness is Qatar's main obstacle on the road to natural sustainability. Despite coming from varying backgrounds, the green stakeholders highlighted issues and challenges close to the individual and called for proper environmental education. An environmentally aware society will not materialize through awareness campaigns alone; more stringent measures, such as penalties and market mechanisms, are needed. Citizens should be at the forefront of awareness-building and behavior-changing measures. Change can only start with this group, who wield power, shape societal norms and rules, and have a permanent stake and strong attachment to their native country. Once certain patterns and standards of behavior are established, the transience of the non-national workforce will cease to be an obstacle for environmentally-sound behavior and consumption.

The experts also saw the need for a more comprehensive involvement of all sectors. The attainment of most of the related NDS goals will not require change beyond the respective government institutions. Of all Qatar's natural sustainability challenges, the green stakeholders collectively were most concerned about the depleting natural water reserves and wasteful natural resource consumption patterns in 
the residential and business sectors, which remain among the least tangibly addressed in current development plans. The exclusive emphasis on environmental justice only as an intergenerational issue also ignores a key dimension, namely that of present environmental justice among the different social strata. Furthermore, an "infrastructure for natural sustainability" is an important area in need of attention. It includes public transport and recycling infrastructures, sustainable recreational spaces and walkways, sustainable urban planning, feed-in-tariffs, and other incentives for green technologies. This is where all the three drivers of natural sustainability come together: technologies, institutions, and people.

By refocusing attention from the economy and growth to the environment and its limits, and from technology and efficiency to institutions, people, and resourcefulness, Qatar and the GCC states might be able to avoid an impending collapse- be it economic or environmental—stemming from their fast exacerbating natural unsustainability. 


\section{BIBLIOGRAPHY}

Al Mulla, Ali Hamed. "Chapter 4: Climate Change and Human Development in Qatar: Issues, Challenges and Opportunities.” Drafted for Qatar's Second Human Development Report, 2009 (Unpublished).

Baker, Susan. Sustainable Development. Oxon: Routledge, 2006.

. "Sustainable Development as Symbolic Commitment: Declaratory Politics and the Seductive Appeal of Ecological Modernisation in the European Union." In The Politics of Unsustainability: Eco Politics in the Post-Ecologist Era, edited by Ingolfur Blühdorn and Ian Welsh, 113-33. Oxon: Routledge, 2008.

Beblawi, Hazem, and Giacomo Luciani, eds. The Rentier State. New York: Croom Helm, 1987.

Blühdorn, Ingolfur, and Ian Welsh, eds. "Eco-Politics beyond the Paradigm of Sustainability: A Conceptual Framework and Research Agenda." In The Politics of Unsustainability: Eco Politics in the Post-Ecologist Era, 1-21. Oxon: Routledge, 2008.

Burke, Sharon. "Natural Security." Working Paper. Washington D.C.: Center for a New American Security, 2009.

Cousins, Ken. "Twenty-Nine Days: Responding to a Finite World." In From Resource Scarcity to Ecological Security, edited by Dennis Pirages and Ken Cousins, 21726. Cambridge: MIT, 2005.

Daly, Herman A. "Economics in a Full World." Scientific American 293 (September 2005): 100-7.

Dieren, Wouter van, ed. Taking Nature Into Account: A Report to the Club of Rome: Toward a Sustainable National Income. New York: Springer, 1995.

General Secretariat for Development Planning (GSDP). Qatar National Vision 2030. Doha: GSDP, 2008.

General Secretariat for Development Planning (GSDP). Advancing Sustainable Development: Qatar National Vision 2030. Second Human Development Report. Doha: GSDP, 2009.

General Secretariat for Development Planning (GSDP). Qatar National Development Strategy 2011-2016. Doha: GSDP, 2012.

Goodland, Robert. "The Concept of Environmental Sustainability." Annual Review of Ecology and Systematics 26 (1995): 1-24.

Hardin, Garrett. “The Tragedy of the Commons.” Science 162 (December 1968): 1243-48. 
Hartwick, John M. "Intergenerational Equity and the Investing of Rents from Exhaustible Resources." The American Economic Review 67 (December 1977): 972-4.

Hvidt, Martin. "Economic and Institutional Reforms in the Arab Gulf Countries." Middle East Journal 65 (Winter 2011): 85-102.

Lahn, Glada, and Paul Stevens. Burning to Keep Cool: The Hidden Energy Crisis in Saudi Arabia. London: Chatham House, 2011.

Luomi, Mari. The Gulf Monarchies and Climate Change: Abu Dhabi and Qatar in an Era of Natural Unsustainability. London: Hurst, 2012.

Meadows, Donella H., Jorgen Randers, and Dennis L. Meadows. Limits to Growth: The 30-Year Update. White River Junction: Chelsea Green, 2004.

Ministry of Environment of Qatar. Initial National Communication to the UNFCCC. Doha: Ministry of Environment, 2011.

Nonneman, Gerd. "Political Reform in the Gulf Monarchies: From Liberalisation to Democratisation? A Comparative Perspective." Working Paper. Centre for Middle Eastern and Islamic Studies. University of Durham, 2006.

Pirages, Dennis. "From Limits to Growth to Ecological Security." In From Resource Scarcity to Ecological Security, edited by Dennis Pirages and Ken Cousins, 1-20. Cambridge: MIT, 2005.

Pirages, Dennis, and Ken Cousins, eds. From Resource Scarcity to Ecological Security. Cambridge: MIT, 2005.

Qatar National Food Security Programme, http://www.qnfsp.gov.qa.

Qatar News Agency. "Qatar to Generate 10 Percent Power from Solar Energy.” May 22, 2012.

Qatar Statistics Authority. http://qsa.gov.qa.

Qatar Statistics Authority. Qatar Social Trends 1998-2010. Doha: Qatar Statistics Authority, 2011.

Qatargas. Pioneer. August 2011.

Raouf, Mohamed A. Economic Instruments as an Environmental Policy Tool: The Case of GCC Countries. Dubai: Gulf Research Center, 2007.

Rockström, Johan, et al. "Planetary Boundaries: Exploring the Safe Operating Space for Humanity." Ecology and Society 14 (2009): 32.

Scheer, Herman. Energy Autonomy; The Economic, Social and Technological Case for Renerwable Energy. London: Earthscan, 2007. 
United Nations Conference on Environment and Development. Rio Declaration on Environment and Development, 1992.

UNFCCC CDM. http://cdm.unfccc.int/.

Wackernagel, Mathis, and William E. Rees. "Perceptual and Structural Barriers to Investing in Natural Capital: Economics from and Ecological Footprint Perspective." Ecological Economics 20 (January 1997): 3-24.

Williams, Colin C., and Andrew C.Millington. "The Diverse and Contested Meanings of Sustainable Development." The Geographical Journal 170 (June 2004): 99104.

World Commission on Environment and Development. Our Common Future. Oxford: Oxford University Press, 1987.

World Resources Institute. "Climate Analysis Indicators Tool." http://cait.wri.org/. June 2011. 


\section{Appendix 1.The Ecological Footprint Index: Methodology and GCC Scores for 2008}

The ecological footprint is a tool for quantitatively measuring humanity's demand on the Earth's resources, ecosystems, and ecosystem services. Its many applications include the ability to measure and indicate at different geographical levels (e.g. world, state, individual) whether our societies and lifestyles are out of balance with ecological carrying capacities at different levels (e.g. world and state). The footprint measures "how much land and water area a human population requires to produce the resource it consumes and to absorb its carbon dioxide emissions, using prevailing technology." $\mathrm{A}$ related concept is biocapacity, which is an indicator of the Earth's regenerative capacity, or its capacity to meet humanity's resource demands and absorb waste and pollution.

The concept was established in the 1990s by Mathis Wackernagel and William Rees. It has since been developed by a number of academics and widely adopted across the world and by a variety of stakeholders. In the GCC, the UAE government has engaged extensively with the methodology, and is using related data for scenariobuilding and in energy policy-making. ${ }^{2}$ Presently, the development of the concept and related data and applications is led by the Global Footprint Network, which produces annual data sets of all countries in the world with a population of over 1 million. The index has been made widely popular and well-known by the international conservation organization WWF, which uses the figures in its Living Planet Reports. ${ }^{3}$

The basic unit of measurement is global hectare (gha). It is useful for quantifying, for example, how much an average person could/should or does consume and pollute, including if we were to divide the world's biocapacity equally. In 2008, according to the Global Footprint Network, there were 1.8 gha available per person. However, the average ecological footprint was 2.7 gha. That year, humanity was using resources and producing waste (most of which were in the form of carbon dioxide emissions) 52\% faster than the Earth can sustain. In other words: "We are living as if we have an extra planet at our disposal. We are using 50 per cent more resources that the Earth can sustainably produce and unless we change course, that number will grow fast-by 2030 even two planets will not be enough."

This imbalance can also be described with the term "overshoot." The world has been in overshoot since 1970 when our total ecological footprint first reached the Earth's carrying capacity. While the average footprint has remained relatively constant (rising from 2.4 gha in 1961 to 2.7 gha in 2008), due to population growth (more

\footnotetext{
${ }^{1}$ Source for the quote and all of the text in this appendix (except parts where source is mentioned): Global Footprint Network website, http://www.footprintnetwork.org

${ }^{2}$ See EWS-WWF et al., UAE Ecological Footprint Initiative (Gland: 2010), 8.

${ }^{3}$ See, for example, WWF, Living Planet Report 2012 (Gland: 2012).

${ }^{4}$ Global Footprint Network, “Global Auction for Natural Resources Heats Up,” press release, May 15, 2012.
} 
than doubling from 3.1 billion in 1961 to 6.7 billion in 2008), available biocapacity has declined to almost half of 1960 s levels ( 3.2 gha to 1.8 gha). ${ }^{5}$ Consequences of overshoot include collapsing fisheries, deforestation, depletion of natural freshwater reserves, and climate change. Recognizing the limits of our planet is a fundamental step to moving away from the current business-as-usual trajectory. The Footprint Network experts assert that economies and societies with "surplus ecological reserves" will be the most resilient and sustainable in the future.

By comparing countries, it is possible do visualize which, on a per capita basis, make the most and least demands on our planet. In the 2012 index, which presents data for 2008, three GCC states (Qatar, Kuwait, and the United Arab Emirates) ranked as the countries with the world's highest ecological footprint: 8.4-11.7 global hectares per person, of which 70-80\% was comprised by carbon dioxide emissions. This was 3-4 times the global average footprint and up to 6.5 times the global carrying capacity-6.5 planets. $^{6}$

National biocapacity naturally also reflects the differences between climatic zones and regions: for example, all the GCC states included in the study, except Qatar, had a biocapacity well below the global average (0.4-0.7 global hectares per person). This means that in the Gulf, demand on resources and ecosystem services is proportionally even higher than in most other regions: GCC states are high "ecological debtors," as defined by the authors of the footprint concept.

Although some environmental impacts are easily attributable to national territories, such as water (in most cases) and land use issues, others take from or pollute shared resources, such as fishing and greenhouse gas emissions. Carbon dioxide forms the largest (and proportionally growing) component of our global footprint. Notably, the footprint indicator only accounts for consumption within a country's borders (i.e. net consumption). It excludes the export industry's footprint, but includes that of all imports. ${ }^{7}$ The small Gulf monarchies, in particular Qatar, have often pointed out that the use of $\mathrm{CO}_{2}$ per capita figures as an indicator of sustainability treats these states unjustly or unequally due to the proportionally important shares of total natural resource consumption and environmental pollution attributable to the energy and other export-oriented industries. The ecological footprint indicator arguably is a fairer and more useful instrument in the sense that it focuses only on local consumption. It also shows that, despite the exclusion of the export industry, the GCC states unfortunately still rank among the world's least naturally sustainable countries.

\footnotetext{
${ }^{5}$ Global Footprint Network, National Footprint Accounts 2011, ed. 1.0 (May 2012).

${ }^{6}$ See Table 1.

${ }^{7}$ Ministry of Environment and Water of the UAE, The UAE Ecological Footprint Initiative: Summary Report 20072010 (Abu Dhabi, EWS-WWF 2011), 12.
} 
Table 1. The GCC States' Ecological Footprint in 2008 in a Global Context.

\begin{tabular}{|l|r|r|r|r|}
\hline \multirow{2}{*}{$\begin{array}{c}\text { Country/region } \\
\text { (footprint ranking in } \\
\text { 2008) }\end{array}$} & \multirow{2}{*}{$\begin{array}{c}\text { Biocapacity, } \\
\text { gha/capita }\end{array}$} & \multicolumn{2}{|c|}{$\begin{array}{c}\text { Ecological footprint, } \\
\text { gha/capita }\end{array}$} & \multirow{2}{*}{$\begin{array}{c}\text { Times global } \\
\text { footprint/global } \\
\text { carrying capacity }\end{array}$} \\
\cline { 3 - 4 } & & $\begin{array}{c}\text { Carbon } \\
\text { footprint }\end{array}$ & $\begin{array}{c}\text { Total } \\
\text { footprint }\end{array}$ & (ii \\
Kuwait (2) & 0.4 & 7.7 & 9.7 & $3.6 / 5.4$ \\
\hline Oman (14) & 2.2 & 3.3 & 5.7 & $2.1 / 3.2$ \\
\hline Qatar (1) & 2.1 & 8.9 & 11.7 & $4.3 / 6.5$ \\
\hline Saudi Arabia (42) & 0.7 & 2.4 & 4.0 & $1.5 / 2.2$ \\
\hline United Arab Emirates (3) & 0.6 & 6.0 & 8.4 & $3.1 / 4.7$ \\
\hline Middle East/Central Asia & 0.9 & 1.4 & 2.5 & $0.9 / 1.4$ \\
\hline High-income countries & 3.1 & 3.4 & 5.6 & $2.1 / 3.1$ \\
\hline World & 1.8 & 1.5 & 2.7 & $1 / 1.5$ \\
\hline
\end{tabular}

${ }^{i}$ Includes the biocapacities of: cropland, grazing land, forest land, fishing grounds, and built up land.

ii Includes the footprint of: cropland, grazing, forest, fish, carbon, and built up land.

Source: Global Footprint Network, National Footprint Accounts 2011, ed. 1.0 (May 2012).

$\mathrm{Nb}$. Data for Bahrain N/A. The index only includes countries with a population of over 1 million. 


\section{Appendix 2. Questions for Green Stakeholders}

\section{Background}

a. Were you part of the preparatory and/or stakeholder engagement processes for the Qatar National Vision 2030 and/or the Qatar National Development Strategy 201116 ?

b. If yes, which areas/pillars or sector strategies were you involved in?

\section{Sustainability of natural resource use (water, energy, land)}

a. In your personal view, is the use of natural resources in Qatar currently sustainable? How or in which ways is it (not)? (Please give concrete examples.)

b. In your personal view, is natural resource use in Qatar environmentally sustainable? If not, what are the major 'unsustainabilities', negative impacts or problems? (Please consider all sectors, from the industry and businesses, through government, to the consumers.)

c. In the view of your institution (government agency, company or other organization), what are the major problems?

\section{Sustainable development priorities}

Among the country's major challenges, identified in the Qatar National Vision 2030 document, is balancing between 'economic growth, social development and environmental management' (p. 3). The Vision goes on to say that 'economic development and protection of the environment are two demands neither of which should be sacrificed for the sake of the other' (p. 8).

a. Do you agree with these statements, if they are understood as defining the ideal relationship between the economy, environment and development? Do you think these ideals are achievable?

\section{Natural resources in the National Development Strategy 2011-16}

The Qatar National Development Strategy 2011-2016 outlines 11 targets in the areas of water and energy [please refer to Appendix 3]:

a. Do you think that the 11 targets are achievable? If not, why?

b. Do you think the targets sufficiently address Qatar's major energy and water-related challenges, with regards to their sustainable use and environmental sustainability? If not, in your view, what is/are the major challenge(s) and what should be done to tackle it/them?

\section{Environmental management in the National Development Strategy 2011-16.}

The Qatar National Development Strategy 2011-2016 outlines 11 targets in the areas of water, air, waste, conservation, urban planning, awareness, governance, and regional 
cooperation [please refer to Appendix 3]:

a. Do you think that the 11 targets are achievable? If not, why?

b. Do you think the strategy's targets address all Qatar's major environmental sustainability challenges? If not, in your view, what is/are the major challenge(s) and what should be done to tackle it/them?

6. Obstacles for environmental sustainability, including natural resource use

What are the three most important obstacles/challenges for achieving a balance between natural resource use and the environment in Qatar?

\section{Responsibility to act}

Please rank in order ( $1=$ most, 6 = least $)$ who, if anyone, in Qatar has the responsibility to initiate change towards environmentally more sustainable consumption patterns: expatriates; Qatari nationals; international businesses; local businesses; industries; government

\section{Environmental management measures and policy instruments}

Please rank in order $(1=$ most, $6=$ least $)$ the most suitable types of environmental management measures for Qatar in the next decade, which will increase the sustainability of natural resource use and enhance environmental sustainability: technological measures/improvements; efficiency improvements; laws and regulation; persuasive measures (e.g. awareness-raising); market-based incentives (e.g. subsidies); market-based disincentives (e.g. tariffs, taxes). 


\section{Appendix 3. Water and Energy Efficiency and Environmental Sustainability Targets in the Qatar National Development Strategy 2011-2016}

Table 2. Efficiency Targets for Water and Energy, the National Development Strategy.

Water efficiency targets for 2013:

- Cut network leaks of desalinated water to $10 \%$ or less from the current estimate of $30 \%-35 \%$.

- Ensure that all water consumption is metered.

- Support installation of water-saving technologies for households and other users.

- Develop a programme of water-saving measures in plans for agricultural development.

- Expand treated sewage effluent networks to increase the use of recycled water.

- Examine the feasibility of industrial wastewater collection and treatment systems.

Energy efficiency targets for 2013:

- Study opportunities to lower gas consumption per unit of combined energy and water produced through enhanced dispatch.

- Improve thermal efficiency in power production.

- Advance the adoption of energy-saving technologies.

- Keep Qatar's green building code implementation on track.

- Establish a committee on renewable energy at the Ministry of Energy and Industry. Water and energy targets for 2014:

- Phase in user charges for power, water and fuel that better reflect the full economic costs of production.

- Establish an independent and integrated water and power regulator.

Source: GSDP, Strategy, 84-5, 89, 92.

Table 3. Environmental Sustainability Targets, the National Development Strategy.

Targets for 2011-2016:

- Enact a comprehensive National Water Act establishing an integrated system of quality requirements, discharge controls and incentives for conservation.

- Monitor groundwater, conserve freshwater aquifers where possible and eliminate excess water in Doha's water table.

- Eliminate instances of excess ozone levels through improved air quality management.

- Halve gas flaring to $0.0115 \mathrm{bcm} / \mathrm{Mt}$ of energy produced from the 2008 level.

- Establish a solid waste management plan, strongly emphasizing recycling.

- Recycle $38 \%$ of solid waste, up from the current $8 \%$.

- Contain domestic waste generation at $1.6 \mathrm{~kg} /$ capita/day.

- Establish a comprehensive electronic biodiversity database.

- Expand actively managed protected areas.

- Establish 3 shady greenspace corridors, monitor effect on urban air quality \& health.

- Build an environmentally aware society.

- Appoint a well-known national champion for the environment to raise awareness and commitment through demonstration projects and conversation partnerships.

- Create a searchable electronic information source at the Ministry of Environment.

- Lead one regional environment effort, and launch two environmental projects involving private sector participation. 


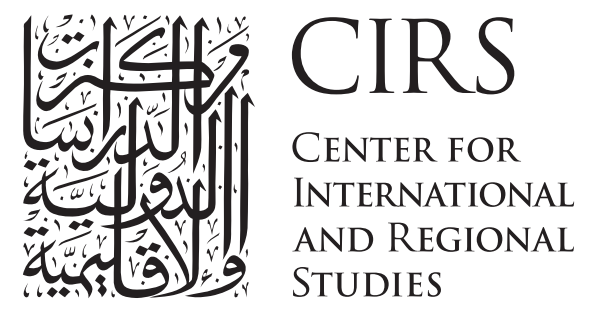

GEORGETOWN UNIVERSITY SCHOOL OF FOREIGN SERVICE IN QATAR

Center for International and Regional Studies Georgetown University School of Foreign Service in Qatar P.O. Box 23689

Doha, Qatar

http://cirs.georgetown.edu

Tel +97444578400

Fax +974 44578401 


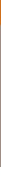

